\title{
THE PROCESS OF DEFINING THE CONCEPT OF SUSTAINABILITY: A CASE STUDY OF THE "HOLDING HANDS" INCOME-GENERATING COMMUNITY PROJECTS IN THE NORTH WEST PROVINCE
}

\author{
C. M. Niesing ${ }^{1 *}$, E. M. Scholtz ${ }^{2}$, A. Kruger ${ }^{3}$ \\ ${ }^{1}$ Ms., Africa Unit for Transdisciplinary Health Research (AUTHeR) Faculty of Health Sciences, \\ North-West University, Potchefstroom, South Africa, christi.niesing@nwu.ac.za \\ ${ }^{2}$ Ms., Potchefstroom Business School, Faculty of Economic Sciences, North-West University, \\ Potchefstroom, South Africa, retha.scholtz@nwu.ac.za \\ ${ }^{3}$ Prof., Africa Unit for Transdisciplinary Health Research (AUTHeR) Faculty of Health Sciences, \\ North-West University, Potchefstroom, South Africa, annamarie.kruger@nwu.ac.za \\ ${ }^{*}$ Corresponding author
}

\begin{abstract}
The problem of poverty is multi-dimensional and has many facets and levels. In South Africa the lack of jobs is adding to this problem. Therefore, a strategy to alleviate poverty is through income-generating community projects. In the evaluation of community projects, it is always an issue to know when a project is sustainable. This study focuses on the "Holding Hands" income-generating community projects in the North West Province of South Africa. The project team accepted the Brundtland definition of sustainability to plan the interventions. However it seems to be important to know what the understanding is of sustainability by the participants to be able to measure progress of the project. The aim of this paper is to establish a demographic profile of a typical member of an income-generating community project in the "Holding Hands" project and to describe their understanding of the concept of Sustainability. The "Holding Hands" incomegenerating community project developed over time since 2001 through Participatory Action Research, including quantitative and qualitative methods. It includes 5 groups of women from the previously disadvantaged communities in different districts of the North West Province of South Africa. A survey was conducted and information on rating aspects of the meaning of sustainability to the project members was collected. Statistical analysis included frequency distributions, correlations and comparisons between different geographical areas. This is the first analysis of this kind done in the "Holding Hands" project. This information creates knowledge about the viewpoint of the indigenous communities in an income generating project and can be used to guide other similar projects towards a realistic planning for success. It can also be useful to influence policy in terms of job creation and entrepreneurship.
\end{abstract}

Keywords: Assets, community development, community projects, disadvantaged communities, incomegenerating projects, indigenous knowledge, livelihoods, poverty, sustainability, sustainability indicators, skills development

\section{INTRODUCTION}

Poverty is identified as a big problem in South Africa and unemployment is recognized as one of the main reasons for the problem (Makhalane, 2009, p. 11). Public deployment programmes are initiated by the South African Government to engage unemployed people with low skill levels in activities that provide some income 
while developing additional skills. This results in various income-generating community projects being initiated on a regular basis in South Africa. These community projects are initiated through government agencies like the National Development Agency (Mayer et al., 2011, p.30). Very few of these projects remain active for a period longer than 10 years (van Niekerk, 2006, pp. 72-74). This indicates that an important obstacle for income-generating community projects to overcome is sustainability.

AUTHeR (Africa Unit for Transdisciplinary Health Research) is a research unit within the Faculty Health Sciences at the North-West University. The FLAGH (Farm Labour and General Health) Programme is a research programme that started in 2001 and is designed to understand the difficulties and inequalities farm workers in the North West Province of South Africa experienced. In 2003 an intervention to teach the wives of farm workers needle crafting started in the FLAGH Programme. This was the birth of the "Holding Hands" income-generating community project. A unique bottom-up approach has been followed by the FLAGH Programme in initiating and developing these projects.

To increase sustainability in the Holding Hands Projects as well as other similar projects in Africa it is important to increase indigenous knowledge concerning the partaking community's views and knowledge on sustainability. To be able to measure progress as well as sustainability for income-generating interventions it is imperative to clarify the definition of sustainability as understood by the participants of the community projects.

This paper reports on the demographic profile of a typical member in an income-generating Holding Hands community project and their understanding of the concept of sustainability. The knowledge collected in this survey resulted in indigenous knowledge about the understanding of and the process of sustainable incomegenerating community development projects in South Africa. This may result in better designed interventions that have optimal impact on future capacity building in South Africa.

\section{MOTIVATION FOR USING INCOME-GENERATING COMMUNITY PROJECTS AS A TOOL TOWARDS COMMUNITY CAPACITY BUILDING}

Poverty seems to be a very difficult concept to define, it has many facets and dimensions and it means different things to different people. Poverty is mostly defined by people who do not live in poverty (Meyiwa, 2010 , p. 127). The concept poverty may be associated and related to unemployment, lack of knowledge, inadequate health care services, a lack of knowledge about nutrition and family planning and a lack of available skills to create an income. Lack of resources and the inability to access resources are therefore indicators of poverty (Mokgotho, 2010, p. 21). Poverty is described as an inability to devise an appropriate coping strategy in a time of economic and social crisis (Kadozo, 2009. p. 16).

Income-generating community projects are one of the strategies used by the South African Government to fight poverty. One of the reasons being that the project could have an immediate effect on the levels of poverty of the participants because the implementation of such a project results in immediate cash inflow and skill development of the participants (Oldewage-Theron, 2012, p. 5). Income-generating interventions focus on the economic development of a community through the use of economic tools. These tools are activated on a small scale by providing access for community members to assets that will help them with economic stimulations in their community (Hortensia, 2008, p. 11).

Sustainable development in income-generating community projects remain a problem for various reasons. The concept of sustainability as defined by the Brundtland report (United Nations, 1987, p. 17): "Sustainable development is development that meets the needs of the present without compromising the ability of future generations to meet their own needs." implies two key aspects. Firstly it related to the needs of people at present and in the case of South Africa it implies the need of the poor. Secondly it is related to time and resources so that the ability of future generations would not be compromised. In resource poor communities, time is mostly no problem, but resources are, including skills. In the world of the developers and funders, it is the other way round and time means money. Most of the time this means a mismatch between developers, funders and the developing community as too little resources are available to allow enough time for developmental projects to become sustainable.

Sustainable development results in achieving a quality of life that will be available for generations, because it is socially desirable in fulfilling the community's social needs, economically viable by paying for itself and ecologically sustainable in using recourses wisely (Makhalane, 2009, p. 11). Bottom-up sustainable community development lies in building community capacity. Indigenous knowledge is seen as a specific community's views regarding the community member's worldviews, spiritual being and ancestral knowledge (Goduka, 2012, p. 7). This knowledge is shared by communities in specific places and communities that have common cultural and social ties. It is seen as the knowledge that the local people use to make a living. 
To ensure successful community capacity building through income-generating community projects, it is very important to gather indigenous knowledge of the community regarding the intervention as well as their views on sustainability.

Building strong networks and partnerships that aim to meet development objectives, as well as the selfreliance of communities, is important. Community development is seen as sustainable when it can cope with shock and stress, has the ability to recover from it while maintaining and enhancing its assets and capabilities. Indigenous knowledge is seen as a key element of social capital in communities that can help in community development in terms of income generation and job creation for community members (Goduka, 2012, p. 7).

Benefits that an income-generating community project can bring to a community includes: It provides primary financial benefits; it provides small, regular cash injections into the household to help pay for immediate needs; it leads to better health and nutrition; it improves self-esteem and provides satisfaction; it strengthens social networks; it prevents isolation; it provides skill transfer to the community (Hortensia, 2008, p.83).

\section{BACKGROUND ON THE FARM LABOUR AND GENERAL HEALTH PROGRAMME}

The FLAGH programme is a follow-up of the previous THUSA -study (Transition, Health and Urbanisation in South Africa) that identified farm dwellers in the North-West Province as an extremely resource poor group (Vorster et al, 2000, p. 506). The main aim of the FLAGH programme is to improve the sustainable livelihood strategies of people living in rural areas in the North-West Province of South Africa through intervention programmes based on multi- and transdisciplinary research (Kruger et al, 2006, P.833; Niesing, 2012, p. 3).

A programmatic approach that consists of a series of projects implemented in a programme may have more sustainable outcomes (Bell and Morse, 2008, p. 92). The FLAGH Programme developed the Holding Hands income-generating community project through the implementation of Participatory Action Research (PAR). PAR is used as a strategy that includes quantitative and qualitative research methods to address vulnerability in communities (van Niekerk and van Niekerk, 2009, p. 130).

A needs analysis was conducted in 2002, followed by in depth skill development. Twelve unemployed women asked for further training in business and sewing skills. The women named their project the Holding Hands project, because they were working together as a team. The Holding Hands project has grown from a small income-generating project to a business servicing a number of regular clients with an extended range of products. The women earn an income from product sales that assists them to improve their food security status. New members are added to the group on a regular basis. New projects that involved more women joined Holding Hands as the project grew. Skills such as beading and the production of paper beads and crocheting with raffia were added. The FLAGH Programme supports the projects in: Training, management of the business, obtaining raw materials, and access to markets, new product development and facilitator support (Niesing, 2012, p. 4).

The indigenous communities that form part of the Holding Hands projects indicated that they would like assistance from the FLAGH Programme in developing capacity in their communities. The communities take ownership of the intervention from inception and the other stakeholders support the implementation of the intervention. This bottom-up approach is essential to ensure sustainability in the developmental process (Meyiwa, 2010, p. 127). This initiation is followed by an asset-based community assessment, where the assets of the community as well as existing skills and opportunities are identified.

The assessment process is done in close collaboration with the indigenous communities that forms part of the intervention. An in-depth needs analysis, supported by community participation, will lead to maximum benefits which will improve the quality of life of the participants (Makghoto, 2010, p.17). This assessment forms the basis from where the income-generating interventions can be developed. From the initial findings of the assessment, a plan is formulated for holistic intervention.

This intervention is based on the sustainable livelihood approach. Cross-sector social partnerships are formed to facilitate stakeholder involvement in the entire project. The intervention is started by presenting the LIFEPLAN® course to the participants and followed by skills development training.

The LIFEPLAN $®$ programme addresses poverty amongst the most vulnerable through human development and training in life skills in order to improve their wellbeing in terms of health, nutrition and choice (Bonthuys et al, 2011, p. 423). After the completion of the skills development training, the facilitator would act as project manager for the new business. The project expands naturally while training as well as other interventions are implemented as and when the project members require it. Progress towards sustainability is measured by 
the use of sustainability indicators, followed by re-planning and implementation of interventions (Niesing, 2012, p. 73).

\section{METHODOLOGY}

This article reports on a part of the results obtained from a study conducted in the Holding Hands incomegenerating community projects developed to measure progress made in the projects from 2002 to 2011 (Niesing, 2012, pp. 1-125). In 2006 a qualitative baseline study was conducted by Van Niekerk (2006). In this study sustainability indicators were developed by using qualitative data collection methods. In 2012 the study was designed to evaluate the sustainability indicators through a quantitative questionnaire that includes open-ended questions by Niesing (2012). An in depth literature study revealed additional sustainability indicators that could impact the projects. The questionnaires were in English. A protocol for collecting data was developed and included the project facilitator to be involved in the data collection process to overcome the language barrier. The researcher has a good relationship with the participants because of a close working relationship for the past four years. Community engagement have been established through the development of the interventions and therefore data collection could begin without further community engagement. The collection of data took place during regular visits to the projects. The project members were not all literate; therefore some of the participants needed help with the completion of the questionnaires (Niesing, 2012, pp. 7-8).

The questionnaire was developed to overcome the literacy barrier of the participants. The questionnaire consists of 2 sections. This article reports on Section A and the first part of section B. Section A focused on demographic information while the first part of section $B$ focused on the definition of sustainability as seen by the project members. The second part of Section B includes the original 19 indicators developed by Van Niekerk (2006) and six new indicators identified from literature. The questionnaire concluded with openended questions regarding the perception of sustainability for their projects by the participants (Niesing and Scholtz, 2013, pp. 36-50).

The study population consisted of the community projects involved in the FLAGH programme. The study population included the three sewing projects around Potchefstroom, as well as the sewing project in Jan Kempdorp and the glass recycling project in Ganspan. All the active members of the community projects were included in the study: the entire population of 35 members. Because of the fact that these participants were actively involved in the community projects, they were best qualified to answer the research questions in this study.

\section{DEMOGRAPHIC PROFILE OF PARTICIPANTS IN THE "HOLDING HANDS" PROJECT}

The projects are geographically situated in rural areas of the North-West Province in South Africa: 3 projects in Potchefstroom and vicinity and two projects in Jan Kempdorp. The Rysmierbult Sewing Project, the Castello Embroidery Project and the Vredefort Dome Sewing Project are situated on farms in the Potchefstroom district with the closest being 45 kilometres from Potchefstroom; the Ganspan Glass Recycling Project and the Jan Kempdorp Sewing Project are found in and around Jan Kempdorp in the Northern Cape. Poverty is a common phenomenon in rural areas (Dyubhele, 2009, p. 21). The population is seen as all the active participants in the Holding Hands income-generating projects.

The ages of the participants vary between 22 and 62 years, with a mean average of 37.44 and a standard deviation of 9.81. This indicates that participants in these income-generating community projects cannot be confined to a certain age group, this is confirmed in another study (Pronyk, 2008, p. 1564).

Thirty of the participants were female and two male. The male members are both part of the Jan Kempdorp Glass Recycling Project. Male members in a female income generating group can help the group to access support that would otherwise have been unobtainable through the use of their social networks (Green, 2008, p. 3). In communities that are severely influenced by poverty it seems that females are more likely to engage in activities that will promote sustainable livelihoods especially in rural areas (Lemke, 2009, p. 200).

Female-headed households are regarded as engines of community development and should therefore be supported in their actions (Dyubhele, 2011, p. 22). Women play the following crucial roles in communities: they act as agents of change and have skills and leadership qualities that influence people's ability to survive and recover. When empowered, women's initiative and creativity create capacity and solutions for grassroots problems (Blewitt, 2008, p.26). Poverty alleviation programmes that focus on income generating projects empower people to tackle their problems and realize their potential. Income generating community 
projects provide community members, especially women, with an income but also access to production assets (Nkosi, 2010, p. 37).

Most of the participants indicated that their first language is Setswana (88\%), IsiXhosa speaking participants' amount to $9 \%$ and IsiZulu speaking participants is 3\%. Most of the participants are able to speak and understand English to some level.

Sustainability of income-generating projects is closely related to the literacy levels of the participants. In the Holding Hands projects the literacy levels vary substantially from members with primary school education only, to those who have finished Grade 12. In a case study of a rural community in the Eastern Cape Woolridge literacy and education levels were found to similar to those of the participants in the Holding Hands projects (Dyubhele, 2011, p. 101). The above-mentioned information may indicate that participation in income-generating community projects is not limited to a low level of education, but that the community members may require additional skills that will enable them to build capacity in their communities. Empowerment and skills development are required to equip the participants to manage the projects in a sustainable manner.

The participants are mostly single, or not married but living with a partner. These categories combined amounted to $45 \%$ of the participants. The findings indicated that $68 \%$ of participants are financially responsible for four or more people. This is a big responsibility for somebody who does not have a permanent income. Similar situations were found in other income-generating community projects with the average household size being 7 people (Pronyk, 2008, p. 1567).

The mental picture created by the demographic information describes an individual who lives in the NorthWest Province, between the age of 22 and 62 and who is likely to be female. The education level of the individual can range from primary school education to Grade 12. This individual most likely does not have the security of a marriage and is most likely financially responsible for more than four people. This mental picture indicates a vulnerable person who does not have the ability to create a coping strategy in times of crises.

When referring to the contributors to poverty described in this article, all of the above factors associated with poverty are present in this profile. The project participants are individuals in the community that acts as agents of change and are nodes of sustainable community development in spite of their circumstances. Interventions should be planned and implemented optimally to empower these individuals to transfer their skills to the community to facilitate holistic community development.

\section{THE MEANING OF THE PROJECT SUSTAINABILITY}

In terms of project sustainability it is critical to define sustainability for the participants of the project. This question was designed to give the participants the opportunity to rate aspects of sustainability previously identified qualitatively. Through focus group discussions the participants identified five aspects that they associated with sustainability in terms of their income-generating community projects. A three point Lickert scale was decided on because of the literacy barrier (Chachamovich, 2009, p. 40).

A universal sign associated with yes and no, the thumbs-up and -down sign, as well as a neutral thumb sign was used to facilitate a response. The participant had the option of a thumbs-up option if the aspect definitely resembled sustainability, a neutral thumb option if the participant was not sure if the aspect resembled sustainability, and a thumbs-down option if the aspect did not resemble sustainability to the participant. The following table summarizes the responses of the participants by depicting, for each aspect of sustainability, the percentage response in each category, the mean response and the standard deviation:

Table 1: Summary of Responses Regarding the Meaning of Project Sustainability

\begin{tabular}{|c|c|c|c|c|c|}
\hline \multicolumn{6}{|c|}{ Summary of Responses Regarding the Meaning of Project Sustainability } \\
\hline $\begin{array}{c}\text { Meaning of } \\
\text { project } \\
\text { sustainability }\end{array}$ & 1 & 2 & Mean & Std. deviation \\
\hline Exposure & $90.6 \%$ & $6.3 \%$ & $3.1 \%$ & 1.13 & 0.421 \\
\hline $\begin{array}{c}\text { Being able to } \\
\text { export products }\end{array}$ & $75 \%$ & $21.9 \%$ & $3.1 \%$ & 1.28 & 0.523 \\
\hline Growth and & $71.9 \%$ & $18.8 \%$ & $9.4 \%$ & 1.38 & 0.660 \\
\hline
\end{tabular}




\begin{tabular}{|c|c|c|c|c|c|}
\hline empowerment & & & & & \\
\hline $\begin{array}{c}\text { Ownership } \\
\text { transferred }\end{array}$ & $50 \%$ & $37.5 \%$ & $12.5 \%$ & 1.63 & 0.707 \\
\hline $\begin{array}{c}\text { Sufficient } \\
\text { income }\end{array}$ & $40.6 \%$ & $37.5 \%$ & $21.9 \%$ & 1.81 & 0.780 \\
\hline
\end{tabular}

A mean closer to 1 indicates that more participants indicated that they associate the particular aspect strongly with sustainability. It is interesting to note that nearly all of the respondents indicated that Exposure means Sustainability to them. Exposure relates to the amount of people that are aware of their project locally and internationally. Being able to Export Products was also indicated as what they understand Sustainability to mean.

Growth and Empowerment is closely related to Sustainability in the literature and is indicated by the participants as aspects that means sustainability to them. This indicates that the participants realize that they have to take ownership of their development to ensure sustainability for their project.

The projects are developed through a bottom-up approach; this may be the reason why Ownership Transferred was not indicated as one of the most important aspects of Sustainability. The participants are involved in the development of the projects from the beginning and the projects are owned by the participants from the start.

Sufficient Income was the aspect that the participants indicated least means sustainability to them. That is an interesting finding, because this indicates that the concept of sustainability in the Holding Hands projects is not necessarily linked to the amount of income that the participants receive. This could indicate that the participants stay involved for reasons other than the income they expect to receive in the projects. These reasons may be linked to concepts like growth and empowerment and self-actualization. When measuring and evaluating the progress that the projects have made towards sustainability it is noted that the project participants sees sustainability as: exposure, being able to export products, growth and empowerment, ownership transferred and sufficient income in that order of importance. This increases indigenous knowledge concerning the views of the community on the definition of the concept sustainability. This knowledge will empower the project members to measure their own progress and to be able to focus the direction that they have to develop to increase the sustainability of the project.

Correlation coefficients were calculated to understand the association between the variables. The Nonparametric Spearman's correlation coefficient ( $r$ ) was used, which is based on ranks of the data and not dependent on the assumption of normality (Field, 2009, p. 180).

When interpreting the correlation coefficient, a correlation coefficient of \pm 0.1 indicates a small, non-practically significant correlation. A correlation coefficient of \pm 0.3 indicates a medium, practically visible correlation and a correlation coefficient of \pm 0.5 indicates a large, practically important correlation (Field, 2009, p. 180).

Correlation coefficients above 0.30 are reported in the table below:

Table 2: Age Correlation with Sustainability Definition

\begin{tabular}{|l|c|c|}
\hline \multicolumn{3}{|c|}{ Sustainability Definitions } \\
\hline Age & Growth and empowerment & -0.33 \\
\hline Age & Being able to export products & $-0.407^{*}$ \\
\hline \multirow{2}{*}{ *. Spearman's rank order correlation is significant at the 0.05 level (2-tailed). } \\
\hline
\end{tabular}

For the sustainability definitions Growth and Empowerment and Being able to Export Products, there was a negative medium practically visible correlation with Age. This indicates that the older participants indicated that Growth and Empowerment is a more important aspect of sustainability to them than younger people. Similar results were found for the ability to Export Products. It is interesting that older participants indicated that growth and empowerment is a more important aspect of sustainability, this may be because of the life experiences they had and the battles concerning growth and empowerment. It was harder for the older generation to receive quality education and also less important for females to become educated. The younger generation may not link the aspect as closely to sustainability because it is easier to achieve. Older participants indicated that the ability to export products is an important aspect concerning sustainability, in 
contrast to younger participants. More research may be required to clarify the reason for this. The abovementioned correlations were the only significant correlations found between the variables in terms of the definition of sustainability.

The following table summarizes the analyses where the mean responses with regard to the definition of sustainability were compared for the two geographical areas the projects are situated in. The Rysmierbult and Castello Sewing Projects are situated in the vicinity of Potchefstroom, and the Jan Kempdorp Sewing and Ganspan Glass Recycling Projects in Jan Kempdorp. The Venterskroon project has been left out of this, because it is in another geographical area and there were only two participants.

Table 3: Difference between Geographical Areas in Terms of Definitions of Sustainability

\begin{tabular}{|c|c|c|c|c|c|c|c|c|}
\hline \multicolumn{9}{|c|}{ Comparison between Jan Kempdorp (J.K) and Potchefstroom (P) projects definition of sustainability } \\
\hline \multirow{2}{*}{$\begin{array}{l}\begin{array}{c}\text { Question } \\
\text { number }\end{array} \\
\text { No. }\end{array}$} & \multicolumn{2}{|c|}{ Mean } & \multicolumn{2}{|c|}{ Standard Deviation } & \multicolumn{2}{|c|}{$\begin{array}{c}\text { Parametric } \\
\text { Independent } \mathrm{t} \text {-test }\end{array}$} & \multicolumn{2}{|c|}{$\begin{array}{c}\text { Non-parametric } \\
\text { Mann-Whitney test }\end{array}$} \\
\hline & $\mathrm{P}$ & J.K & $\mathrm{P}$ & J.K & $\mathrm{p}$ & $\begin{array}{l}\text { Effect } \\
\text { size (d) }\end{array}$ & $\mathrm{p}$ & $\begin{array}{l}\text { Effect } \\
\text { size }(r)\end{array}$ \\
\hline $\begin{array}{l}\text { Ownership } \\
\text { transferred }\end{array}$ & 2.00 & 1.29 & 0.52 & 0.73 & 0.01 & 0.98 & $<0.01$ & 0.58 \\
\hline $\begin{array}{l}\text { Sufficient } \\
\text { income }\end{array}$ & 2.13 & 1.57 & 0.81 & 0.65 & 0.05 & 0.69 & 0.06 & 0.35 \\
\hline $\begin{array}{l}\text { Growth and } \\
\text { empowerment }\end{array}$ & 1.25 & 1.29 & 0.58 & 0.47 & 0.85 & 0.06 & 0.61 & 0.09 \\
\hline $\begin{array}{l}\text { Being able to } \\
\text { export } \\
\text { products }\end{array}$ & 1.38 & 1.21 & 0.50 & 0.58 & 0.43 & 0.28 & 0.22 & 0.23 \\
\hline Exposure & 1.00 & 1.29 & 0.00 & 0.61 & 0.10 & 0.47 & 0.06 & 0.35 \\
\hline
\end{tabular}

A d-value of \pm 0.2 indicates a small - non-practically significant difference, a d-value of \pm 0.5 indicates a medium -practically visible difference. A d-value of \pm 0.8 indicates a large - practically significant difference (Ellis, 2003, p. 53). As nonparametric test, the Mann-Whitney test with its $p$-values and effect sizes $(r)$ are reported. The nonparametric effect sizes can be interpreted as follows: (Field, 2009, p. 180), an effect size of $+/-0.1$ indicates a small, non-practically significant difference, an effect size of $+/-0.3$ indicates a medium practically visible difference and an effect size of $+/-0.5$ indicates a high practically significant difference.

When accessing the definitions of sustainability, it is apparent that the groups answered differently on two aspects. First Ownership transferred with a d-value of 0.98 , a large practically important difference and a non-parametric effect size of 0.58 that indicates a large practically important difference. When analysing the mean of each group, it is apparent that the Potchefstroom group associates this definition less strongly with sustainability, while the Jan Kempdorp groups strongly associated this definition with sustainability. The above suggests that the two groups differed in their view of this aspect of sustainability. The second aspect is Sufficient Income with a d-value of 0.69 , indicating a medium practically visible difference and a nonparametric effect size of 0.35 that indicates a medium practically visible difference. The Potchefstroom groups associated this definition less strongly with sustainability, while the Jan Kempdorp groups strongly associated this definition more with sustainability.

These different viewpoints may be explained by the lifespan of the different projects. The Potchefstroom groups have all been in existence for more than 5 years, where the Jan Kempdorp projects are relatively young projects, about 2 years old. The indigenous knowledge about livelihoods and business management may differ because of the locations of the projects, because this knowledge is shared by communities in specific places and communities that have common cultural and social ties (Goduka, 2012, p. 7). 


\section{CONCLUSION}

The opportunity to research the Holding Hands income-generating community projects provides a unique opportunity to influence poverty through developing high-impact interventions that facilitate sustainable community development. The frequency distribution of the demographic information of the participants provided a profile of a typical person that takes part in the Holding Hands project. The profile of the participants are mostly that of a vulnerable female with a limited education who are responsible to feed more than 4 individuals. Even though these participants are all resource poor, they actively engage in activities that help them implement coping strategies in times of crises. They act as nodes for sustainable development in communities. Therefore it is imperative to empower these individuals to maximise their ability as agents of change in the communities by tailoring interventions specifically to empower them. These interventions should be planned to turn their weaknesses such as limited education into strengths and to empower them to implement their strengths, such as their resilience in a way that will have maximum impact in terms of sustainable community development.

Indigenous knowledge regarding the Holding Hands income-generating projects defining the concept of sustainability has been enriched. The concept of sustainability as defined by the Holding Hands projects rated according to importance is: Exposure; Being able to export products; Growth and empowerment; Ownership transferred; Sufficient income.

It is noticeable that of the 5 terms related to the concept of sustainability, the least important term was sufficient income, therefore it can be assumed that sustainability may not be directly correlated to the amount of income received by the participants, but that they conceptualize their project as being sustainable even if they do not receive sufficient income. The correlations found between the terms of the concept and age of the participants indicated that older participants rated the term Growth and Empowerment is a more important aspect of sustainability than younger participants, similar results were found for the term ability to Export Products.

Even between the geographical sites of the projects the participants differed in their rating of the importance of the terms. The term Ownership transferred was less associated with the concept of sustainability for the Potchefstroom group, while the Jan Kempdorp groups strongly associated this term with the concept of sustainability. Sufficient income as term of the concept of sustainability for the Potchefstroom groups was associated less strongly with sustainability, while the Jan Kempdorp groups strongly associated the term of sufficient income with the concept of sustainability. Insight into what the concept of sustainability actually means for the Holding Hands income-generating community projects is crucial when considering expansion and growth; it gives purpose and direction to the projects.

When considering measurement and evaluation in terms of progress made by the project, this definition must be used as baseline when measuring project impact and progress. In the event of building new funding relationships it will enable the projects to nurture relationships with funders that have the same view on sustainability as the projects. If applying the same concept in other projects it may prove that incomegenerating community projects are actually more sustainable than originally thought because the correct definition of the term sustainability applies to the measuring and evaluation process.

\section{REFERENCE LIST}

Bell, S., \& Morse, S. (2008). Sustainability Indicators. Measuring the Immeasurable? . Cornwall

UK: TJ International.

Blewitt, J. Ed. (2008). Community, Empowerment and Sustainable Development. Cornwall UK: TJ International

Bonthuys, A., Botha, K. F. H., Nienhaber, A. W., Freeks, F. E. \& Kruger, A. (2011). "The Effect of The LIFEPLAN® Programme on the Psychological Wellbeing of a Rural Community in South Africa". Journal of Psychology in Africa. 21 (3).

Chachamovich, E., Fleck, M. P., \& Power, M. (2008). "Literacy Affected to Adequately Discriminate Among Categories in Multipoint Likert Scales". Journal of Clinical Epidemiology. 62 (2009).

Dyubhele, N. S. (2011). "The survival strategies of unemployed rural women: a Case study of Wooldridge". PHD - Business and Economic Sciences. Port Elizabeth: Nelson Mandela Metropolitan University. South Africa.

Ellis, S. M. \& Steyn, H. S. (2003). "Practical Significance (Effect Sizes) Versus or in Combination with Statistical Significance (P-Values)". Management Dynamics. 12 (4). 
Field, A. (2009). Discovering Statistics Using SPSS. 3rd Ed. London: Sage Publications.

Goduka, N. (2012). "Re-Discovering Indigenous Knowledge - Ulwazi Lwemveli for Strengthening Sustainable Livelihood Opportunities within Rural Contexts in the Eastern Cape Province". Indilinga: African Journal of Indigenous Knowledge Systems. 11 (1).

Green, J. M. (2008). Trials and tribulations of setting up a community energy shop in a rural area, KwazuluNatal: Lessons learnt. http://timetable.cput.ac.za/_other_web_files/_cue/DUE/2007/PDF/015M_Green.pdf Date of access: 8 March 2012.

Hortensia, M. C. B. (2008). "Income generating NGOs in post-apartheid South African townships: What role and challenge in poverty reduction? A case study of Women for Peace, Kagiso". Dissertation Masters in Arts. Johannesburg. University of Witwatersrand. South Africa

Kadozo, N. (2009). "Sustainable livelihood approaches: The future for income generating projects in urban areas? An evaluation of five income generating projects in Tembisa. Dissertation" - Master's Degree. Pretoria: UNISA. South Africa

Kruger, A., Lemke, S., Phometsi, M., Van't Riet, H., Pienaar, A.E. \& Kotze, G. (2006). "Poverty and Household Food Security of Black South African Farm Workers: Legacy of Social Inequalities". Public Health Nutrition, 9 (7).

Lemke, S., Bellows, A.C. \& Heuman, N. (2009). "Gender and Sustainable Livelihoods: Case Study of South African Farm Workers". Innovation and Sustainable Development. 4 (2/3).

Mayer, J.M., Gordhan, S., Manxeba, R., Hughes, C., Foley, P., Maroc, C., Lolwana, P., \& Nell, M. (2011). Development Planning Division Working Paper Series no. 28. Johannesburg: Development Bank of Southern Africa

Makhalane, V. (2009). "The assessment of factors contributing to the sustainability of poverty relief projects in the Eastern Cape". Dissertation - Master's Degree. Port Elizabeth: Nelson Mandela Metropolitan University. South Africa.

Meyiwa, T. \& Ngubentombi, S. (2010). "Reflecting on Research Practices and Indigenous Community Benefits for Poverty Alleviation Purposes in the Eastern Seaboard Regions of South Africa". Indilinga: African Journal of Indigenous Knowledge Systems. 9 (2).

Mokgotho, R. F. (2010). "Problems affecting the sustainability of income-generating project at Hlatlolang ABET Centre". Dissertation - Master's Degree Polokwane: University of Limpopo. South Africa.

Niesing, C.M. (2012). E"valuation of sustainability indicators used in the Holding Hands community project in the North West province". Dissertation - MBA. Potchefstroom: NWU. South Africa.

Niesing, C.M. \& Scholtz, E.M. (2013). "Income-generating community projects: The role of motivation and sustainability". In Bisschoff, C.A., Ed. Human capital management. Potchefstroom:North-West University. p. 36-50.

Nkosi, Z. E. (2010). "The impact of income generating projects on women in Utrech"t. Dissertation Master's Degree. Empangeni: University of Zululand. South Africa.

Oldewage-Theron, W. and Slabbert, T, J, C. (2010). "Depth of Poverty in an Informal Settlement in the Vaal Region, South Africa". Health SA Gesondheid. 15 (1).

Pronyk, P. M., Harpham, T., Busza, J., Phetla, G., Morison, L.A., Hargreaves, J. R., Kim, J. C., Watts, H. C. \& Porter, J. D. (2008). "Can Social Capital Be Intentionally Generated? A Randomized Trail from Rural South Africa". Social Science \& Medicine. 67.

United Nations. (1987). "Report of the World Commission on Environment and Development: Our Common Future". http://www.un-documents.net/our-common-future.pdf

Van Niekerk, L. (2006). "Women's income-generating activities in a disadvantaged farming community: Towards sustainability". Dissertation - Masters in Consumer Sciences. Potchefstroom: NWU. South Africa.

Van Niekerk, L. \& van Niekerk, D. (2009). "Participatory Action Research: Addressing Social Vulnerability of Rural Women through Income-Generating Activities". JAMBA: Journal of Disaster Risk Studies. 2(1).

Vorster, H.H., Wissing, M.P., Venter, C.S., Kruger, H.S., Kruger, A., Malan, N.T., De Ridder, J.H., Veldman, 
F.J., Steyn, H.S., Margarets, B.M. \& Macintyre, U. (2000). "The Impact of Urbanization on Physical, Physiological and Mental Health of Africans in the Northwest Province of South Africa: The THUSA Study". South African Journal of Sciences. (96). 